\title{
Duplicate Bladder Exstrophy With Fistula: A Rare Variant of Exstrophy-Epispadias Complex
}

\section{Bijay Thapa}

Department of Paediatric Surgery, Kanti Children Hospital, Maharajgunj, Kathmandu, Nepal

\section{Correspondence:}

Bijay Thapa

Department of Paediatric Surgery,

Kanti Children Hospital,

Maharajgunj, Kathmandu, Nepal

Email: bijaytapa@hotmail.com

DOI: $10.3126 /$ jnps.v41i2.30752

Submitted on: $2020-08-06$

Accepted on: 2021-02-26

Acknowledgements: None

Funding: Nil

Conflict of Interest: None declared

Permission from IRB: Yes
To cite this article: Thapa B. Duplicate Bladder Exstrophy With Fistula: A Rare Variant Of Exstrophy-Epispadias Complex. J Nepal Paediatr Soc. 2021;41(2):282-5.

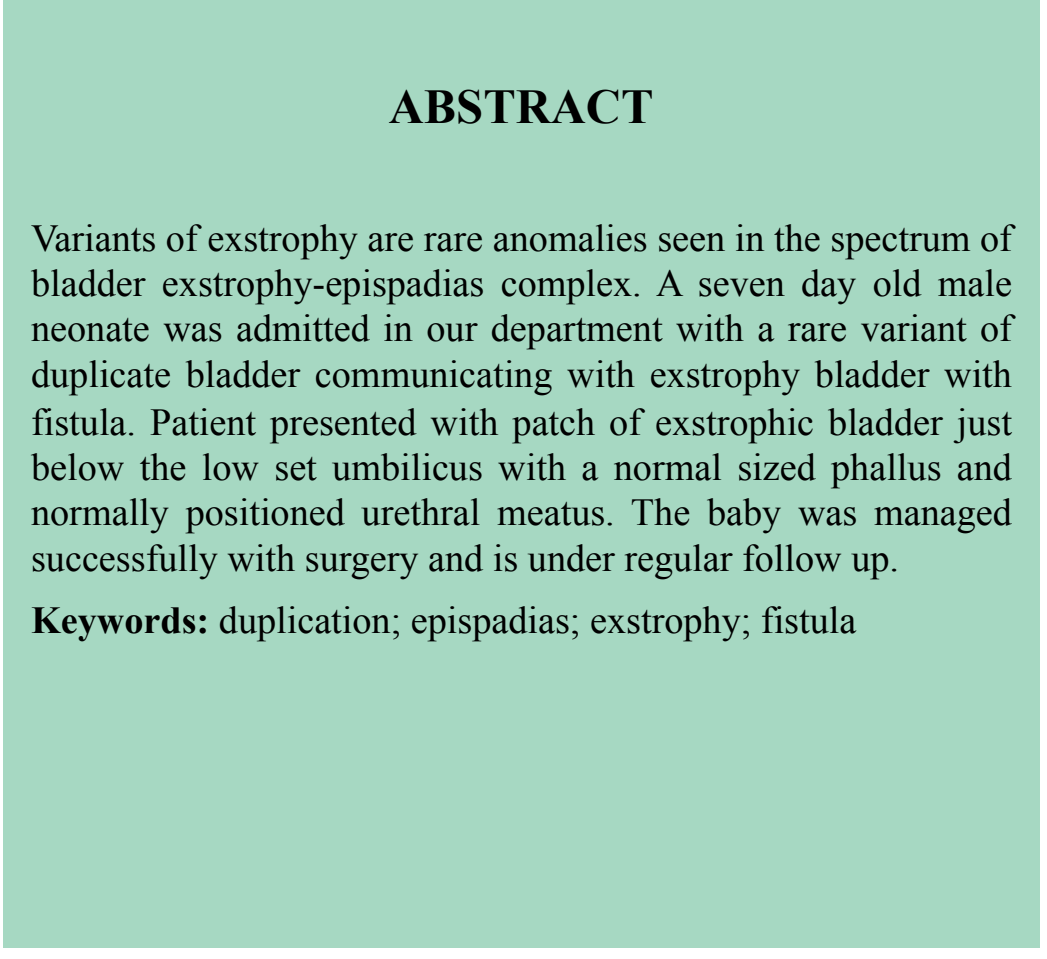

This work is licensed under creative common attribution 3.0 license 


\section{INTRODUCTION}

Bladder exstrophy is a rare malformation occurring predominantly in males, with an incidence of 1:50,000 live births. ${ }^{1}$ Variants of exstrophy bladder constitute only $10 \%$ of cases among them. Duplicate exstrophy is one of the rarest variants within the spectrum of bladder exstrophy. It is characterised by the presence of a non-functional exstrophic mucosal plate on the abdominal wall, with a normal bladder and no exposed ureteric orifices. ${ }^{2,3}$ We report a rare variant of duplicate exstrophy with a fistula between the exstrophy bladder and normal abdominal bladder in a male neonate.

\section{CASE REPORT}

A seven day old male neonate with birth weight 3 $\mathrm{kg}$ was admitted in our surgical ICU with an obvious urogenital abnormality. He was born to 23 years old mother with full term normal vaginal delivery with no significant antenatal and family history. On examination, red and moist bladder mucosa of about $3 \mathrm{~cm}$ in diameter was seen just below the umbilicus with separation of rectus through which urine was seen to flow. Penile length was normal and well formed with orthotopic meatus. Child was passing urine normally per urethra. Both the testicles were palpable in scrotum and there was no other anomaly present. There was a mucosal extension along the dorsum of penis

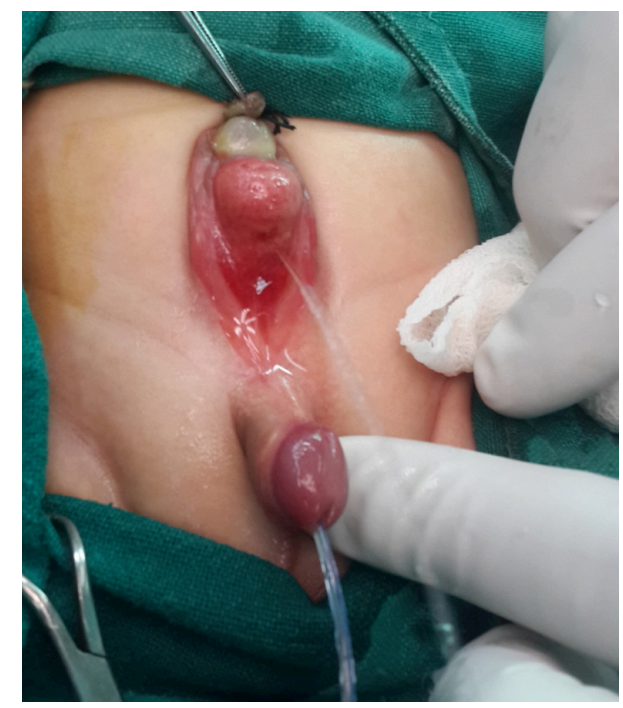

Figure 1. Epispadias urethra of exstrophied bladder which appeared to be epispadias urethra of exstrophied bladder and mild dorsal chordee was present (Figure 1).

His postnatal ultrasound demonstrated normal kidneys, ureters and bladder, beneath exstrophied bladder patch. Child was catheterised and surprisingly, catheter came out from midline through mucosal patch. The plain abdominal radiograph film showed a widened symphysis pubis. All baseline investigations were normal.

For management, surgical exploration was done under general anaesthesia. A midline orifice from where urine leaked was identified and cannulated with an infant feeding tube Figure 2. The exstrophy bladder mucosa was opened longitudinally tracing the fistula tract. Extrophied bladder mucosa excised completely and fistulous tract to normal bladder excised and ligated. As the separation of recti was not wide, the abdominal closure was done tension free without the need of osteotomy. Dorsal chordee and mucosal extension was left for future intervention if needed.

Postoperatively, catheter was taken out on fifth day. Child passed urine normally with a good stream. The ultrasonography and micturating cystourethrogram at six months of age showed normal bladder with normal upper urinary tracts.

\section{DISCUSSION}

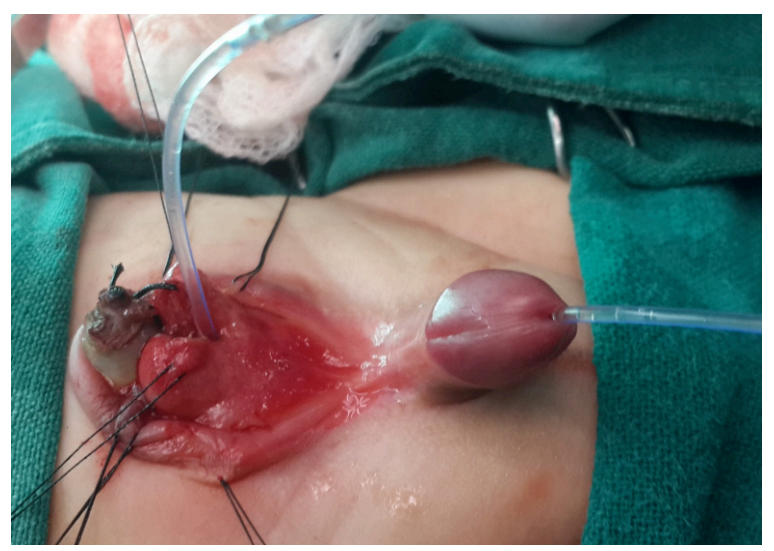

Figure 2. A midline orifice from where urine leaked was identified and cannulated with an infant feeding tube 
Exstrophy variants can be categorised as duplicate exstrophy, superior vesicle fistula, pseudo exstrophy and covered exstrophy. Duplicate exstrophy is one of the rarest variants. ${ }^{1}$ There are two different forms of duplication: antero-posterior duplication and side by side duplication. The first form is suprapubic exstrophic mucosal plate and a covered normal bladder lying in the pelvis with both ureters opening in it as in our case. The second type is associated with classical findings of exstrophy complex. ${ }^{3}$

Duplicate exstrophy was first described by Marshall and Muecke in 1962 as the anteroposterior variety of duplicate exstrophy, where the exstrophied bladder plate is accompanied by a normal phallus and an underlying intact bladder. ${ }^{4}$ The ureters do not drain into the exstrophied bladder. Superior vesicle fistula consists a small communication between the normal bladder and exstrophied bladder as seen in our case. ${ }^{5,6}$ Our case seems even rarer variant as it has combination of both duplicate bladder exstrophy and superior vesical fistula.

Similar case was reported by Tomita et al where the exstrophy variant was the hybrid of duplicate bladder exstrophy and superior vesical fistula. They operated it as classical bladder exstrophy and performed bilateral posterior iliac osteotomies which we didn't do in ours. ${ }^{7}$ We just did simple excision and closure of abdominal wall defect with good post-operative result. Bouali et al. have reported duplicate exstrophy in a female newborn who was managed by simple excision of the exstrophy bladder without osteotomy like ours. ${ }^{8}$ Exstrophy variants may be associated with other congenital anomalies like esophageal atresia, anorectal malformation, umbilical hernia, urethral atresia, spinal dysraphism etc. ${ }^{9}$ However, we could not find any such associated anomalies in our case.

\section{CONCLUSIONS}

Exstrophy variants are extremely rare and thus full pre-operative evaluation is important because treatment and prognosis are entirely different from classical exstrophy. The variant which we described was managed with simple excision of extrophied bladder without osteotomies with good functional and cosmetic result. This case report adds a case further to the scarce literature for rare variants of bladder exstrophy.

\section{REFERENCES}

1. Gearhart JP. Exstrophy, epispadias and other bladder anomalies. In Walsh PC, Retik AB, Vaughan ED Jr.et al eds. Campbell's Urology. 8th ed. Philadelphia, WB Saunders. 2005; 2136-2196.

2. Turner WR, Ransley PG, Bloom DA. Variants of the exstrophic complex. Urol Clin North Am. 1980;7:493-501. PMID: 7404880

3. Sheldon CA, McLorie GA, Khoury A, Churchill BM. Duplicate bladder exstrophy: a new variant of clinical and embryological significance. J Urol. 1990;144(2):334-6. DOI: https://doi.org/10.1016/S0022-5347(17)39447-8

4. Marshall VF, Muecke EC. Variations in exstrophy of the bladder. J Urol. 1962;88:766-96. DOI: https://doi.org/ 10.1016/S0022-5347(17)64883-3

5. Lowentritt BH, Van Zijl PS, Frimberger D, Baird A, Lakshmanan Y, Gearhart JP, et al. Variants of the exstrophy complex: a single institution experience. J Urol. 2005;173:1732-7. DOI: https://doi.org/10.1097/01.ju. $0000154353.03056 .5 \mathrm{c}$

6. Khemchandani SI. Duplicate Bladder Exstrophy with Superior Vesical Fistula in a Male Infant, A Rare Variant. SM J Pediatr Surg. 2016;2(1):1008. Corpus ID: 212463780

7. Tomita SS, McTiernan TL, Ginsburg HB. An unusual form of duplicate bladder exstrophy. J Pediatr Surg. 2010; 45:834-6. DOI: 10.1016/j.jpedsurg.2010.01.006.

8. Bouali O, Mouttalib S, Abbo O Jr, Lemasson F, Moscovici J, Galinier P. Unusual duplicate bladder exstrophy in a female newborn: a case report. J Pediatr Surg. 2012; 47:9-11. DOI: 10.1016/j.jpedsurg.2012.03.067 
9. Gupta DK, Charles AR, Srinivas M. Exstrophy variants: should they be considered malformation complexes separate from classic exstrophy? Eur J Pediatr Surg. 2003;13:377-82. DOI: 10.1055/s-2003-44726 